\title{
Cardiovascular Risk in Metabolically Healthy and Unhealthy Obese Nigerians
}

\author{
Odum E.P. ${ }^{1}$, Asekomeh E.G. ${ }^{2}$, Young E.E ${ }^{3}$ \\ $M B B S, F M C P a t h ; M B B S, M S c, M P H, F W A C P ; M B B S, F W A C P$ \\ ${ }^{I}$ Department of Chemical Pathology, University of Port Harcourt Teaching Hospital, Port Harcourt, Rivers \\ State. \\ ${ }^{2}$ Chevron Clinic, Port Harcourt, Rivers State. \\ ${ }^{3}$ Department of Medicine, University of Nigeria, Enugu Campus, Enugu State.
}

\begin{abstract}
The clustering of obesity with other cardiovascular disease (CVD) risk factors has been described in various ways as the metabolic syndrome. However, a sub-set of obese people with none of these risk factors have been classified as metabolically healthy obese (MHO).

The aim of this study was to investigate CVD risk factors in obese subjects with and without metabolic syndrome and the significance of metabolically healthy obesity.

Clinical measurements of body mass index, blood pressure and waist circumference were carried out in 307 subjects, of which 150 were obese and 157 non-obese. Fasting blood glucose and lipids were measured.

About $69.3 \%$ of the obese subjects did not have any of the risk criteria for metabolic syndrome (MHO). The difference in risk factors for the two groups was mostly significant for hypertension, abdominal obesity, low $H D L$, impaired fasting glucose and type 2 diabetes. The $\mathrm{MHO}$ were similar to the non-obese controls in all risk factors except hypertension and abdominal obesity.

The presence of metabolic syndrome in the obese subjects resulted in a highly increased prevalence of cardiometabolic risk factors, while the $\mathrm{MHO}$ were similar to non-obese subjects in most of the risk factors.

Keywords: Cardiovascular risk, metabolically healthy, metabolically unhealthy, obese Nigerians.
\end{abstract}

\section{Introduction}

Obesity is now recognized as a medical condition and not simply a body type. This is because over the years, several studies have emerged which have linked obesity with increased risk of developing many medical conditions including cardiovascular disease, type 2 diabetes, dyslipidaemia, osteoarthritis, poor mental health and some cancers [1]. Obesity has also been linked with increased mortality. Obesity is currently described as an epidemic with rapidly increasing prevalence in many countries and across all age groups [2]. Among US adults, the prevalence is said to have risen sharply from $15 \%$ in the 1970 s to an estimated $34 \%$ in 2009-2010 [2]. It is estimated that 1.12 billion people worldwide could be obese by 2030, about $20 \%$ of the world's adult population. Central obesity, in particular, is a major risk factor for the development of type 2 diabetes mellitus (T2D), hypertension, metabolic syndrome and cardiovascular disease (CVD) [3-6].

It has been observed that obesity-related metabolic abnormalities do not affect all obese individuals. About 10\%-25\% of obese people are spared [7]. This group has been termed 'metabolically healthy obese' (MHO) individuals and they have a normal metabolic profile similar to that of healthy lean individuals [7]. Recent studies have demonstrated that the risk of developing type 2 diabetes and CVD is greatly increased in obese individuals that have insulin resistance and/or multiple risk factors than in those without insulin resistance or multiple risk factors. Metabolically healthy obese subjects are defined as insulin sensitive, with normal blood pressure, normal glucose metabolism and a favourable lipid profile $[7,8]$. They have been reported to have a less adverse metabolic profile and outcome than obese subjects with metabolic syndrome as well as than normal weight individuals with metabolic syndrome [7].

Metabolic syndrome is defined as a cluster of risk factors which have been shown to act in concert to increase an individual's risk of developing cardiovascular disease. Though defined in various ways, insulin resistance or central obesity is regarded as the main abnormality [9-12].

The Healthy Obese Project (HOP) is a project designed to gain insights into the characterization, determinants and consequences of healthy obesity [13]. In the first phase, 163,517 individuals in ten population cohorts across Europe were studied. They used the NCEP-ATP III criteria to make a diagnosis of the metabolic syndrome and reported considerable variation in the occurrence of metabolically healthy obesity across the different European populations even when unified criteria or definition were applied [13].

The aim of this study was to investigate the differences in cardiometabolic risk factors in obese subjects with and without the metabolic syndrome. We further investigated the differences in the risk factor profile of metabolically healthy obese persons and non-obese controls. 


\section{Subjects And Methods}

The study population was made up of a total of 150 obese subjects selected from patients attending the General Outpatient and Metabolic Clinics of the University of Port Harcourt Teaching Hospital (UPTH) and 157 non-obese controls which included apparently healthy volunteers consecutively enrolled from hospital staff, medical students and relatives of patients attending the metabolic, general and medical out-patient clinics of UPTH. Ethical approval was obtained from the hospital's Research Ethical Committee.

Informed consent was given by participants and necessary clinical information was obtained from them with the use of a standardized pretested questionnaire. Individuals below 18 years, pregnant, acutely or chronically ill, having a history of diabetes mellitus or cardiovascular disease, heavy smokers and alcoholics were excluded. After a brief general examination, the blood pressure (BP) of each participant was measured using a standard mercury sphygmomanometer, waist circumference (WC) was measured just above the iliac crest and body mass index (BMI) was estimated from the height and weight.

Venous blood samples were collected after an overnight fast. Fasting plasma glucose (FPG) concentration was determined using the glucose oxidase method and plasma triglyceride, total cholesterol and high density lipoprotein (HDL)-cholesterol were estimated by enzymatic methods. Low density lipoprotein (LDL)-cholesterol was calculated from the Friedewald formula [14].

The following definitions were used in this study:

Obesity: Defined as BMI $\geq 30 \mathrm{Kg} / \mathrm{m}^{2}$ and classified as class I obesity (BMI of 30.0-34.9), class II obesity (BMI of 35.0-39.9) and class III obesity (BMI $\geq 40)$ [15].

Hypertension: Defined as systolic blood pressure equal to or above $140 \mathrm{mmHg}$ and diastolic blood pressure equal to or above $90 \mathrm{mmHg}$ [15].

Metabolic Syndrome: Based on the NCEP-ATP III (2005) definition, any three or more of the following criteria: hyperglycaemia ( $\mathrm{FPG} \geq 5.6 \mathrm{mmol} / \mathrm{L}$ ), abdominal obesity (WC $>102 \mathrm{~cm}$ in men and $>88 \mathrm{~cm}$ in women), blood pressure $\geq 130 / 85 \mathrm{mmHg}$, triglyceride $(\mathrm{TG}) \geq 1.7 \mathrm{mmol} / \mathrm{L}, \mathrm{HDL}<1.0 \mathrm{mmol} / \mathrm{L}$ (men) and $<1.3 \mathrm{mmol} / \mathrm{L}$ (women) [16].

Impaired fasting glucose: FPG: $6.1-6.9 \mathrm{mmol} / \mathrm{L}[16]$.

Type 2 diabetes (screen-detected): Based on a FPG $\geq 7.0 \mathrm{mmol} / \mathrm{L}$ [4].

Dyslipidaemia: Defined as any one or more of hypercholesterolaemia (plasma total cholesterol $\geq 5.2 \mathrm{mmol} / \mathrm{L}$ ), hypertriglyceridaemia (plasma triglyceride $\geq 1.7 \mathrm{mmol} / \mathrm{L}$ ), high LDL (plasma LDL-cholesterol $\geq 2.6 \mathrm{mmol} / \mathrm{L}$ ) and low HDL (HDL-cholesterol $<1.0 \mathrm{mmol} / \mathrm{L}$ ) [15].

\section{Statistical Analysis}

Statistical analysis was done using the Statistical Package for Social Sciences (SPSS) software version 17.0 (SPSS Inc., Chicago, Illinois, USA). Means of continuous variables were compared using the unpaired student-t test and expressed as mean \pm standard deviation (SD). Frequencies and percentages were obtained for categorical variables. Pearsons chi square or Fishers exact test as appropriate was used to test for differences between categorical variables. Binary logistic regression analysis was used to identify factors that were significantly associated with obesity (using the BMI) and also factors associated with metabolic syndrome among obese subjects. Findings were presented as odds ratio (OR), its $95 \%$ confidence interval (CI) and corresponding $\mathrm{p}$-values. A level of $\mathrm{p} \leq 0.05$ was considered statistical significant in all analyses.

\section{Results}

Among the 157 non-obese controls, $104(66.2 \%)$ were normal weight (BMI: $18.5-24.9 \mathrm{~kg} / \mathrm{m}^{2}$ ) and 53 (33.8\%) were overweight (BMI: $\left.25.0-29.9 \mathrm{~kg} / \mathrm{m}^{2}\right) .8(5.1 \%)$ had metabolic syndrome.

Obese subjects were stratified by the presence of metabolic syndrome. Forty-six (30.7\%) had metabolic syndrome and 104 (69.3\%) did not have metabolic syndrome. Those with metabolic syndrome were older, had a greater severity of obesity, abdominal obesity, a higher mean blood pressure and fasting plasma glucose, and lower HDL than the obese subjects without metabolic syndrome (MHO subjects). Their mean triglyceride, total cholesterol and LDL were not significantly different (Table 1).

Compared to the MHO, obese subjects with metabolic syndrome had a higher prevalence of abdominal obesity, hypertension, low HDL, hypercholesterolaemia, impaired fasting glucose, hypertriglyceridaemia and type 2 diabetes, but the MHO had a slightly higher prevalence of high LDL (Fig. 1). Those with metabolic syndrome also had a 4- to 27 -fold higher risk of having low HDL, hypertension, type 2 diabetes, abdominal obesity, hyperglycaemia and impaired fasting glucose in order of increasing risk (Table 2).

When the MHO subjects were compared with non-obese controls they had a greater severity of risk factors (Table 3) and higher prevalence of abdominal obesity, hypertension, dyslipidaemia and hyperglycaemia but a lower prevalence of IFG and type 2 diabetes (Table 4). This difference was statistically significant only for hypertension $(\mathrm{OR}=3.61 ; 95 \% \mathrm{CI}=1.98-6.59 ; \mathrm{p}<0.001)$ and abdominal obesity $(\mathrm{OR}=20.87 ; 95 \% \mathrm{CI}=10.36$ $-42.05 ; \mathrm{p}<0.001$ ) (Table 4). 
Table 1: Cardiometabolic risk factors of obese subjects stratified by the presence of metabolic syndrome

\begin{tabular}{|llll|}
\hline Risk Factor & $\begin{array}{l}\text { Obese with MS (n=46) } \\
\text { Mean } \pm \text { SD }\end{array}$ & $\begin{array}{l}\text { MHO }(\mathbf{n}=104) \\
\text { Mean } \pm \text { SD }\end{array}$ & P \\
Age (years) & $45.9 \pm 9.7$ & $41.2 \pm 12.1$ & $0.033^{*}$ \\
Body mass index $\left(\mathrm{Kg} / \mathrm{m}^{2}\right)$ & $37.9 \pm 6.3$ & $33.5 \pm 5.0$ & $0.001^{*}$ \\
Waist circumference $(\mathrm{cm})$ & $110.7 \pm 10.8$ & $102.6 \pm 9.2$ & $<0.001^{*}$ \\
Systolic blood pressure $(\mathrm{mmHg})$ & $140.3 \pm 21.8$ & $127.9 \pm 20.5$ & $0.007^{*}$ \\
Diastolic blood pressure $(\mathrm{mmHg})$ & $92.7 \pm 13.1$ & $84.6 \pm 14.6$ & $0.005^{*}$ \\
Fasting plasma glucose $(\mathrm{mmol} / \mathrm{L})$ & $6.0 \pm 2.0$ & $4.8 \pm 0.7$ & $0.001^{*}$ \\
Triglyceride $(\mathrm{mmol} / \mathrm{L})$ & $1.1 \pm 0.6$ & $0.9 \pm 0.3$ & 0.077 \\
High density lipoprotein $(\mathrm{mmol} / \mathrm{L})$ & $1.2 \pm 0.4$ & $1.4 \pm 0.4$ & $0.014^{*}$ \\
Total cholesterol $(\mathrm{mmol} / \mathrm{L})$ & $4.2 \pm 1.2$ & $4.2 \pm 1.2$ & 0.877 \\
Low density lipoprotein $(\mathrm{mmol} / \mathrm{L})$ & $2.4 \pm 1.0$ & $2.4 \pm 0.9$ & 0.918 \\
\hline
\end{tabular}

*Statistically significant $\mathrm{P} \leq 0.05 ; \mathrm{SD}$ - Standard deviation; MS- Metabolic syndrome

$\mathrm{MHO}$ - metabolically healthy obese

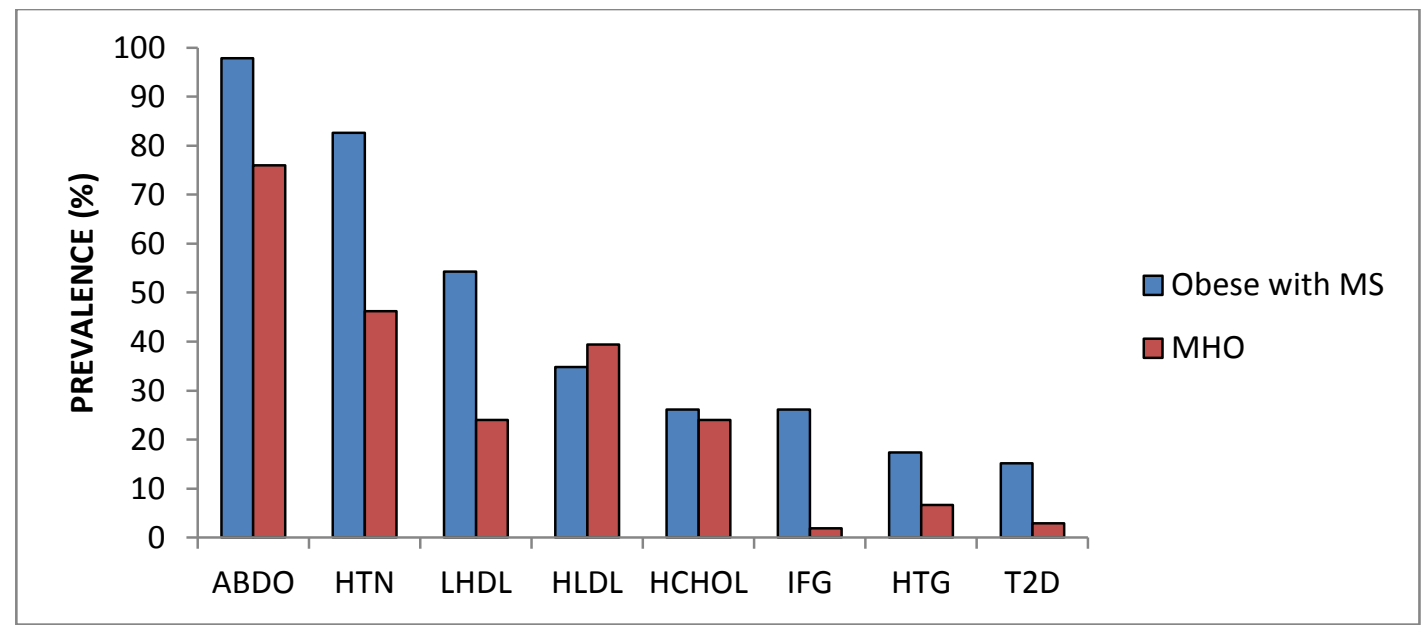

Figure 1: Cardiometabolic comorbidities of obese subjects stratified by metabolic syndrome

MS-metabolic syndrome; MHO-metabolically healthy obese; ABDO-abdominal obesity; HTNhypertension; LHDL-low high density lipoprotein; HLDL-high low density lipoprotein; HCHOLhypercholesterolaemia; IFG-impaired fasting glucose; HTG-hypertriglyceridaemia; T2D-type 2 diabetes.

Table 2: Binary logistic regression of CVD risk factors in obese subjects with and without metabolic

\begin{tabular}{|c|c|c|c|c|c|}
\hline Risk Factors & $\begin{array}{l}\text { Odds } \\
\text { Ratio }\end{array}$ & $\begin{array}{l}95 \% \\
\text { interval }\end{array}$ & $\begin{array}{l}\text { Wald } \\
\text { statistic }\end{array}$ & $\begin{array}{l}\text { Degrees of } \\
\text { freedom }\end{array}$ & $\mathbf{P}$ \\
\hline Age $(\geq 45$ years $)$ & 3.30 & $1.42-7.64$ & 7.72 & 1 & $0.005 *$ \\
\hline Hypertension & 5.47 & $2.03-14.72$ & 11.30 & 1 & $0.001 *$ \\
\hline Abdominal obesity & 10.24 & $1.31-80.24$ & 4.91 & 1 & $0.027 *$ \\
\hline Hyperglycaemia & 12.14 & $4.46-33.06$ & 23.87 & 1 & $<0.001 *$ \\
\hline Impaired fasting glucose & 27.00 & $3.26-233.82$ & 9.33 & 1 & $0.002 *$ \\
\hline Type 2 diabetes & 6.38 & $1.17-34.75$ & 4.59 & 1 & $0.032 *$ \\
\hline Low HDL & 4.08 & $1.73-9.64$ & 10.30 & 1 & $0.001 *$ \\
\hline Hypertriglyceridaemia & 3.04 & $0.86-10.78$ & 2.97 & 1 & 0.085 \\
\hline Hypercholesterolaemia & 1.16 & $0.46-2.93$ & 0.10 & 1 & 0.754 \\
\hline High LDL & 0.84 & $0.36-1.94$ & 0.17 & 1 & 0.677 \\
\hline
\end{tabular}

* Statistically significant $\mathrm{P} \leq 0.05$

Table 3: Cardiometabolic risk factors of MHO subjects and controls

\begin{tabular}{|llll|}
\hline Risk Factor & $\begin{array}{l}\text { MHO } \\
(\mathbf{n}=104) \\
\text { Mean } \pm \text { SD }\end{array}$ & $\begin{array}{l}\text { Controls }(\mathbf{n}=\mathbf{1 5 7}) \\
\text { Mean } \pm \text { SD }\end{array}$ & \\
Age (years) & $41.2 \pm 12.1$ & $34.2 \pm 13.1$ & $<$ \\
Body mass index $\left(\mathrm{Kg} / \mathrm{m}^{2}\right)$ & $33.5 \pm 5.0$ & $23.5 \pm 2.9$ & $<0.001^{*}$ \\
Waist circumference $(\mathrm{cm})$ & $102.6 \pm 9.2$ & $81.1 \pm 10.0$ & $<0.001^{*}$
\end{tabular}


Cardiovascular Risk in Metabolically Healthy and Unhealthy Obese Nigerians

\begin{tabular}{|c|c|c|c|}
\hline Systolic blood pressure (mmHg) & $127.9 \pm 20.5$ & $118.1 \pm 17.0$ & $<0.001 *$ \\
\hline Diastolic blood pressure (mmHg) & $84.6 \pm 4.6$ & $76.8 \pm 11.8$ & $<0.001 *$ \\
\hline Fasting plasma glucose $(\mathrm{mmol} / \mathrm{L})$ & $4.8 \pm 0.7$ & $4.5 \pm 1.2$ & $<0.001^{*}$ \\
\hline Triglyceride (mmol/L) & $0.9 \pm 0.3$ & $0.8 \pm 0.4$ & $<0.001 *$ \\
\hline High density lipoprotein (mmol/L) & $1.4 \pm 0.4$ & $1.4 \pm 0.4$ & 0.136 \\
\hline Total cholesterol (mmol/L) & $4.2 \pm 1.2$ & $4.0 \pm 1.0$ & 0.081 \\
\hline Low density lipoprotein (mmol/L) & $2.4 \pm 0.9$ & $2.2 \pm 0.8$ & $0.030 *$ \\
\hline
\end{tabular}

*Statistically significant $\mathrm{P} \leq 0.05$; $\mathrm{SD}$-standard deviation

Table 4: Comparison of prevalence of cardiometabolic comorbidities of MHO subjects with that of controls

\begin{tabular}{|llll|}
\hline Risk Factor & $\begin{array}{l}\text { MHO (n=104) } \\
\text { Number }(\%)\end{array}$ & $\begin{array}{l}\text { Controls }(\mathbf{n}=157) \\
\text { Number }(\%)\end{array}$ & P \\
Abdominal obesity & $79(76.0)$ & $21(13.4)$ & $<0.001^{*}$ \\
Hypertension & $48(46.2)$ & $30(19.1)$ & $<0.001^{*}$ \\
Hypertriglyceridaemia & $7(6.7)$ & $5(3.2)$ & 0.245 \\
Hypercholesterolaemia & $25(24.0)$ & $23(14.6)$ & 0.096 \\
High LDL & $41(39.4)$ & $47(29.9)$ & 0.150 \\
Low HDL & $25(24.0)$ & $32(20.4)$ & 0.567 \\
Hyperglycaemia & $11(10.6)$ & $13(8.3)$ & 0.575 \\
Impaired fasting glucose & $2(1.9)$ & $4(2.5)$ & 0.526 \\
Type 2 diabetes & $3(2.9)$ & $6(3.8)$ & 0.632 \\
\hline
\end{tabular}

*Statistically significant P $\leq 0.05$; MHO - metabolically healthy obese; LDL - Low density lipoprotein; HDL High density lipoprotein.

\section{Discussion}

This was a cross sectional study carried out in a cohort of obese individuals with and without metabolic syndrome, to determine the frequency and severity of risk factors for cardiovascular disease in them.

The prevalence of cardio-metabolic risk factors in obese subjects was mostly contributed by abdominal obesity and hypertension while type 2 diabetes contributed the least. About $69.3 \%$ of the obese did not fulfill the criteria for metabolic syndrome and were regarded as metabolically healthy obese.

It has been reported that the MHO have lower cardiovascular risk and mortality than other obese individuals especially if physically active [17]. The absence of risk criteria for metabolic syndrome in the MHO individuals suggests the absence of insulin resistance in them. Insulin resistance is the major pathogenetic risk factor for cardiovascular disease. The risk of abdominal obesity was as high as 10 fold in the obese with metabolic syndrome when compared with the MHO. This buttresses the fact that insulin resistance is likely to be the main underlying mechanism for metabolic syndrome in the obese subjects. This is because insulin resistance has been shown to have a strong correlation with abdominal obesity as measured by the waist circumference $[8,18]$.

In addition the obese with metabolic syndrome also had a higher prevalence of CVD risk factors than the MHO. The risk of dyslipidaemia, hypertension, diabetes and impaired fasting glucose was up to 4- to 27fold increased in them when compared to the MHO. MHO subjects were observed to have lower blood pressure, lower FPG, lower triglyceride and higher HDL, all within desirable limits, than obese with metabolic syndrome. However these parameters were still higher in the MHO subjects in reference to non-obese controls. These findings buttress evidence from recent studies which indicate that metabolic syndrome augments type 2 diabetes and CVD risk in obese subjects [8,9].

Non-obese controls however, were observed to have a higher prevalence of impaired fasting glucose (2.5\%) and type 2 diabetes $(3.8 \%)$. When the prevalence of control individuals was re-analyzed with the exclusion of those that were overweight and those with metabolic syndrome, the prevalence of impaired fasting glucose and type 2 diabetes reduced to $2 \%$ and $1 \%$ respectively, indicating that overweight and metabolic syndrome may have accounted for the observed increase. Individuals with metabolic syndrome, irrespective of their weight category, have been demonstrated to have a worse metabolic profile and higher risk of diabetes and CVD than individuals without metabolic syndrome $[7,8]$.

Previous studies have shown that obesity is particularly associated with hypertriglyceridaemia, low HDL and hypercholesterolaemia [7,12]. In this study, prevalence of dyslipidaemia was mostly accounted for by 
elevated LDL and low HDL rather than raised triglyceride. The mean triglyceride value was not different between obese with metabolic syndrome and MHO. This pattern has been reported as a triglyceride paradox in blacks [19]. This paradox describes a phenotype of insulin resistance without raised triglyceride levels. It is postulated that this is due to increased activity of the enzyme lipoprotein lipase in blacks leading to triglyceride clearance [19]. It was also observed that unlike in other populations, insulin resistance did not have a significant effect on lipoprotein lipase hence allowing clearance of triglyceride by the enzyme resulting in the paradox of low triglyceride levels in the presence of insulin resistance.

\section{Conclusion}

There was a significant difference in the prevalence of cardiometabolic risk factors between obese subjects with metabolic syndrome and the obese without metabolic syndrome (MHO). This difference was more marked in risk factors such as abdominal obesity, hypertension, low HDL and elevated LDL but less with hypercholesterolaemia, raised triglyceride, impaired fasting glucose and type 2 diabetes. The major contributors to cardiovascular risk and metabolic syndrome were abdominal obesity and hypertension.

The metabolically healthy obese (MHO), though had more risk factors than the non-obese, were quite similar to them in many characteristics and differed significantly only with abdominal obesity and hypertension.

The above findings suggest that the adverse effect of obesity on cardiovascular disease risk is markedly elevated in the presence of features of the metabolic syndrome. Hence the concept of metabolically healthy obese. This concept is indeed intriguing as a case of 'one size does not fit all'. However in such persons, counseling on adoption of a healthy life-style is likely to be beneficial as they may still develop cardiovascular risk factors with time. Large scale population-based longitudinal studies on the future risk of developing cardiovascular disease in these individuals will be necessary to elucidate the need or otherwise for further interventions in them.

\section{References}

[1]. Swinburn BA, Sacks G, Hall KD, McPherson K, Finegood DT, Moodie ML et al. The global obesity pandemic: shaped by global drivers and local environments. Lancet 2011;378:804-814.

[2]. Ogden CL, Carroll MD, Kit BK, Flegal KM: Prevalence of obesity in the United States, 2009-2010. NCHS Data Brief 2012, 1-8.

[3]. Misra A, Khurana L. Obesity and the Metabolic Syndrome in developing countries. J ClinMetab, 93(11), 2008, S9-S30.

[4]. Yumuk VD, Hatemi H, Tarakci T, Uyar N, Turan N, Bagriacik N, Ipbuker A. High prevalence of obesity and diabetes mellitus in Konya, a central Anatolian city in Turkey. Diabetes Res Clin Pract, 70, 2005, 151-158.

[5]. Whitlock G, Lewington S, Sherliker P, Clarke R, Emberson J, Halsey J et al. Body mass index and cause-specific mortality in 900,000 adults: collaborative analyses of 57 prospective studies. Lancet 2009; 373: 1083-1096.

[6]. Mokdad AH, Ford ES, Bowman BA, Dietz WH, Vinicor F, Bales VS et al. Prevalence of obesity, diabetes and obesity-related health risk factors. 2001. JAMA 2003; 289: 76-79.

[7]. Pajunen P, Kotronen A, Korpi-Hyovalti E, Keinanen-Kiukaanniemi S, Oksa H, Niskanen L et al. Metabolically healthy and unhealthy obesity phenotypes in the general population: the FIN-D2D survey. BMC Public Health 2011;11:754-762.

[8]. Meigs JB, Wilson PF, Fox CS, Vasan RS, Nathan DM, Sullivan LM, D’Agostino RB. Body mass index, metabolic syndrome and risk of type 2 diabetes or cardiovascular disease. J Clin Endocrinol Metab, 91(8), 2006, 2906-2912.

[9]. "World Health Organization. Definition, diagnosis and classification of diabetes mellitus and its complications: Report of a WHO Consultation. Part 1: diagnosis and classification of diabetes mellitus. 1999 Last accessed on 2011 Jun 03World Health Organization: Geneva, Switzerland. Available from: http://www.whqlibdoc.who.int/hq/1999/ WHO_NCD_NCS_99.2.pdf."

[10]. "National Institutes of Health: Third Report of the National Cholesterol Education Program Expert Panel on Detection, Evaluation, and Treatment of High Blood Cholesterol in Adults (Adult Treatment Panel III). Executive Summary. Bethesda, MD, National Institutes of Health, National Heart, Lung and Blood Institute. 2001; (NIH publ. no. 01-3670).”

[11]. "Einhorn D, Reaven GM, Cobin RH, Ford E, Ganda OP, Handelsman Y, et al., authors. American College of Endocrinology position statement on the insulin resistance syndrome. Endocr Pract. 2003;9:237-52."

[12]. "The IDF consensus worldwide definition of the metabolic syndrome." Accessed on 11 April, 2014. "Available from: http://www.idf.org/webdata/docs/IDF Meta def final.pdf."

[13]. Van Vliet-Ostaptchouk, Nuotio ML, Slagter SN, Doiron D, Fischer K, Foco L et al. The prevalence of metabolic syndrome and metabolically healthy obesity in Europe: a collaborative analysis of ten large cohort studies. BMC Endocrine Disorders 2014; 14:9.

[14]. Friedewald WT, Levy RI, Fredrickson DS. Estimation of the concentration of low-density lipoprotein cholesterol in plasma without the use of preparative ultracentrifugation. Clin Chem. 1972; 18: 499-502.

[15]. Iloh GP, Ikwudinma AO, Obiegbu NP. Obesity and its cardio-metabolic co-morbidities among adult Nigerians in a Primary Care Clinic of a Tertiary Hospital in South-Eastern Nigeria. J Fam Med Primary Care 2013;2:20-26.

[16]. Odum EP, Orluwene CG. Metabolic syndrome prevalence in healthy individuals in university of Port Harcourt teaching hospital (UPTH), port Harcourt. IOSR-Journal of Dental and Medical Sciences 2013;10:17-22.

[17]. Hamer M, Stamatakis E: Low-dose physical activity attenuates cardiovascular disease mortality in men and women with clustered metabolic risk factors. Circ Cardiovasc Qual Outcomes 2012, 5:494-499.

[18]. Behan KJ, Mbizo J. The relationship between waist circumference and biomarkers for diabetes and CVD in healthy non-obese women. The Pensacola study. Labmedicine, 38(7), 2007, 422-427.

[19]. Sophia S.K. Yu, B.S. Darleen C. Castillo, B.S. Amber B. Courville et al. The Triglyceride paradox in people of African descent. Metab Syn Rel Dis 2012; 10: 77-82. 